\title{
Jornalismo de dados na revista Realidade
}

\section{Marcos Antônio Zibordi}

\section{Resumo}

Pretendemos discutir a produção de reportagens com base estatística entre 1966, ano de estreia da revista Realidade, e 1973, quando mudou radicalmente. Da consulta a originais coligimos informações como regularidade, extensão e metodologia das reportagens numéricas, classificando 40\% como "jornalismo de dados". Sua decisiva presença confronta a ideia de uma revista tomada de narrativas jornalísticoliterárias, produzidas por insubstituível equipe nos dois primeiros anos. As conclusões resultam, sobretudo, da aplicação dos parâmetros de análise de Mancini e Vasconcellos (2016), segundo os quais narrativas numéricas devem atender a três "dimensões": investigativa, interpretativa e comunicativa.

\section{Palavras-Chave}

Revista Realidade. Jornalismo de dados. Reportagem.

\section{Marcos Antônio Zibordi}

Doutor em Ciências da Comunicação pela Universidade de São Paulo USP. Professor da Faculdade Cásper Líbero e da Escola de Comunicação da USP, São Paulo, SP, Brasil. E-mail: mzibordi@hotmail.com https://orcid.org/0000-0003-4818-2117

\section{Parâmetros e rebatimentos}

\section{da abordagem}

0 objetivo deste artigo é descrever e discutir 0 uso de dados na produção de reportagens pela revista Realidade, publicação que pode ter sido pioneira no gênero ao utilizar estatísticas com finalidades jornalísticas no Brasil. Enquanto publicou conteúdo informativo relevante, levantamentos numéricos foram tão importantes quanto as ferramentas subjetivas de captação, redação e edição, exaltadas pela maioria das pesquisas. Na tentativa de cumprir o objetivo proposto, começamos situando dimensões fundamentais. A primeira delas é que discutir jornalismo de dados na revista Realidade implica, forçosamente, estender o recorte recorrente das pesquisas sobre a história da publicação, temporalmente fixadas nos dois primeiros anos.

Por isso cobrimos desde a estreia da revista, em 1966, até 1973, quando passou por uma mudança radical, com diminuição do formato e pasteurização do conteúdo. Compreender 0 
aspecto relegado das reportagens leva-nos a enfrentar questões de datação, embora não constituam nosso interesse principal.

Do ponto de vista contemporâneo relativo ao foco deste artigo, a produção de narrativas numéricas é crescentemente discutida e ensinada nas escolas de Jornalismo. Na imprensa, os dados aparecem cada vez mais embasando coberturas jornalísticas, chegando ao livro-reportagem como a obra Políticos do Brasil, de Fernando Rodrigues (2006), que parte das declarações de Imposto de Renda de representantes eleitos para demonstrar 0 crescimento de seus patrimônios.

A produção bibliográfica teórica cresce, inclusive no sentido de aproximar acadêmicos e profissionais. Considerando que uma das principais pretensões do jornalismo de dados é ser científico, fonte indispensável para discutir os equívocos comuns entre repórteres e cientistas é a obra Ciência e Jornalismo - da herança positivista ao diálogo dos afetos, de Cremilda Medina (2008). Por sua vez, a coletânea Jornalismo investigativo e pesquisa científica: fronteiras (CHRISTOFOLETTI, KARAM, 2015) reúne jornalistas e pesquisadores brasileiros e argentinos problematizando a inevitável aproximação entre as duas áreas. Nessas e em outras referências arroladas, há o reiterado alerta quanto às armadilhas que vão de aspectos metodológicos a posturas deslumbradas, como o jornalista argentino que nos lembra a necessidade de evitar o tom de "coisa sagrada" das investigações e narrativas (2015, p. 101).

A propósito, do ponto de vista metodológico, a definição de narrativa aplicada às reportagens de dados de Realidade procura abarcar desde a escrita até combinações complexas de textos, mapas, gráficos, fotos e desenhos. Nessas narrativas, a relação entre as partes deve ser determinada pela causalidade, ou seja, "cada unidade encontra seu lugar na narrativa porque houve ou porque há tal outra unidade" (TODOROV, 1971, p. 52).

Os elementos narrativos são correlativos, o que significa, por exemplo, que a inserção de estatísticas em uma reportagem deve equilibrar números, imagens e palavras. Mais do que organização, a narrativa jornalística de dados requer organicidade. Quando ela não ocorre, reprovaremos 0 excesso de dados em determinados textos de Realidade, por excederem seu papel de parte encaixada, prejudicando, a princípio, a indispensável fluência, que não mera questão de estilo, pois define a natureza sequencial da narrativa.

Por outro lado, apontamos como notáveis vários textos, infográficos e outras construções de narrativas visuais cujos encaixes fazem das 
"relações espaciais elementos que constituem a organização" (TODOROV, 1971, p. 61). Dito de outra forma, as partes encaixadas surgem "engastadas no interior de outra que as engloba" (LOPES E REIS, 1988, p. 156).

Para Todorov, o processo de encaixe explicita a "propriedade mais profunda de toda a narrativa".

Mas qual é a significação interna do encaixe, por que todos esses meios se encontram reunidos para the dar importância? A estrutura da narrativa nos fornece a resposta: 0 encaixe é uma explicitação da propriedade mais profunda de toda a narrativa. Pois a narrativa encaixante é a narrativa de uma narrativa. Contando a história de uma outra narrativa, a primeira atinge seu tema essencial e, ao mesmo tempo, se refere nessa imagem de si mesma; a narrativa encaixada é ao mesmo tempo a imagem dessa grande narrativa abstrata da qual todas as outras são apenas partes ínfimas, e também da narrativa encaixante, que a precede diretamente. Ser a narrativa de uma narrativa é 0 destino de toda narrativa que se realiza através do encaixe. (TODOROV, 1969, p. 126).

Esse imbricamento entre as partes (aspecto sintático) está relacionado a outro parâmetro teórico com finalidades metodológicas neste artigo: a obrigatória e específica referência jornalística embasando a avaliação das coberturas de dados em Realidade. Para isso, utilizamos as três categorias analíticas de Mancini e Vasconcellos (2016), aplicáveis aos aspectos qualitativos (ou semânticos) das narrativas numéricas, que são as competências para investigar, interpretar e comunicar.
Esses requisitos serão verificados no processo de produção de jornalismo de dados que começa nas estatísticas, passa pela transformação dos números em narrativas e chega à capacidade de transmissão e assimilação das mesmas. Atuar na dimensão investigativa significa buscar ou produzir conjuntos numéricos. Eles precisam ser expostos em suas relações de causa e consequência, o que revela capacidade de interpretação. A dimensão comunicativa está interessada na transmissão e compreensão de dados pelo leitor através de textos e imagens.

Quanto aos procedimentos metodológicos práticos, compreender o jornalismo de dados em Realidade implicou a leitura e a anotação das edições mensais originais dos seis primeiros anos, gerando tabela de matérias (Tabela 1). Não foi difícil detectar esses textos, em geral os mais importantes, destacados desde a capa. Consideradas somente as chamadas principais, a média é de cinco coberturas significativas de dados em doze edições anuais. Isso significa que pouco mais de $40 \%$ do conteúdo jornalístico publicado por Realidade no período analisado têm como base levantamentos quantitativos: formulários por correspondência, enquetes presenciais e por telefone, informações de documentos oficiais. Exatamente metade das reportagens está entre as principais, considerando as edições regulares e as temáticas - e 23 de 30 matérias estão estampadas na capa. As estatísticas foram coligidas, sobretudo, por empresas 
especializadas em pesquisas de opinião

pública, mas também pela redação.

A anotação inicial, considerando mês, ano e posição das chamadas, evidenciou a regularidade e a importância do jornalismo de dados na revista, conteúdo perene e valorizado, conforme demonstrará a tabela de reportagens compiladas. A linguagem jornalística com base estatística foi mantida e cresceu durante os sete primeiros anos do projeto editorial da revista.

Na mesma tabela estão indicados os procedimentos metodológicos de cada levantamento estatístico que lastreou narrativas jornalísticas numéricas em Realidade. Anotamos o universo pesquisado, a amplitude geográfica, o tempo utilizado para a realização dos levantamentos, os tipos de questionários aplicados, o nome dos responsáveis pelas estatísticas, além do total de páginas dedicadas à cobertura.

Também selecionamos trechos exemplares de reportagens numéricas, tanto pelo que consideramos editorialmente adequado, quanto 0 contrário, sempre com base nos parâmetros de investigação, interpretação e comunicação de Mancini e Vasconcellos (2016). Essas citações aparecerão ao discutirmos a capacidade narrativa de Realidade quando realizou coberturas com dados. As informações sobre as reportagens e as metodologias foram indexadas numa planilha eletrônica do tipo Excel.

\section{Uma Realidade a explorar}

A manutenção da linha editorial da revista

e, especificamente, a produção crescente

de jornalismo de dados, é o critério editorial mais importante para justificar nosso recorte temporal, entre 1966 e 1973. Nesses sete anos, narrativas numéricas são recorrentes em Realidade, ultrapassando o recorte fixado nos dois anos iniciais por consagrada bibliografia (FARO, 1999; FREIRE, 2002; KUCINSKI, 2003; MORAES, 2007; LIMA, 2009; MARÃ0, RIBEIRO, 2010; FERREIRA, 2013; SEVERIANO, 2013).

Não pretendemos reinventar, mas ampliar a interpretação da revista apontando qualidades, mas também limitações estilísticas que levantam sérios senões a várias reportagens de Realidade, publicação supostamente impecável, outra combatível cristalização interpretativa. Em várias coberturas estatísticas, o encaixe de números entre palavras foi excessivo, por exemplo.

Houve, contudo, edições célebres baseadas em dados, como a que abordou a Amazônia, vencedora do Prêmio Esso de Jornalismo de 1972 na honrosa categoria de "melhor contribuição à imprensa". Foi 0 coroamento de uma das principais ferramentas de construção da veracidade da informação jornalística em Realidade, que tinha poder econômico para encomendar pesquisas de opinião pública que fossem pautadas ou pautassem a redação. Mapas, gráficos e outras narrativas visuais a partir de 
estatísticas também são notáveis, sobretudo no final do período analisado por este artigo, entre 1966 e 1973.

Verificamos, portanto, continuidade de linhas editoriais fundamentais de Realidade além dos dois primeiros anos, pelo menos no que diz respeito à produção de jornalismo de dados. Essa distorção dos fatos e do próprio processo jornalístico na então maior editora do país, a Abril, brota de ampliação injustificada da fundamental abordagem da revista realizada por Faro (1999).

Faro começa, necessariamente, pelo primeiro número de Realidade, de abril de 1966, avançando até dezembro de 1968, quando o governo militar edita seu quinto Ato Institucional, o AI-5, considerado o golpe dentro do golpe devido ao recrudescimento institucional. Relevantes pesquisas repetiram esse recorte temporal de Faro, entre 1966 e 1968. Apoiada nessa demarcação, Moraes (2007) analisa as cartas dos leitores e, no prefácio do seu trabalho, reforça que houve uma "primeira fase" de Realidade (p. 13). Essa reiteração temporal aparece ainda em obras de ex-jornalistas da revista, como no livro da dupla José Hamilton Ribeiro e José Carlos Marão (2010) e no de Mylton Severiano (2013).

Porém, contra a ideia de uma primeira fase contrapomos, em primeiro lugar, a continuidade do projeto editorial de publicar jornalismo de dados, além do inconteste fato de que demissionários importantes retornaram logo após pedirem demissão, como os três autores citados anteriormente. 0 nome de José Hamilton Ribeiro, repórter-símbolo de Realidade, consta novamente no expediente da revista em abril de 1969, cinco meses após o pedido de demissão da equipe inicial.

Outros profissionais que ocuparam cargoschave, como Audálio Dantas, corroboram com interpretação segundo a qual o projeto editorial inicial teve continuidade, apesar da demissão coletiva do final de 1968:

$$
\begin{aligned}
& \text { A partir de 1969, quando eu fui para a revista, } \\
& \text { eu acho que até } 72 \text { por aí, a revista continuou } \\
& \text { sendo uma publicação importante. Apesar de } \\
& \text { ter perdido algumas de suas estrelas, dos seus } \\
& \text { grandes repórteres, mas vieram outros. Diga- } \\
& \text { mos que a primeira equipe tinha um sentido } \\
& \text { maior de unidade, ela pensava mais em bloco, } \\
& \text { como se dizia, o "Pasquim" falava: "racioci- } \\
& \text { nava em bloco". Mas de qualquer maneira a } \\
& \text { revista continuou, tanto é que foi aí, em } 70 \text { ou } \\
& 71 \text {, que se produziu talvez o trabalho mais im- } \\
& \text { portante da revista Realidade, que foi a edição } \\
& \text { da Amazônia, pelo Raimundo Rodrigues Pe- } \\
& \text { reira, que sem dúvida foi e continua sendo um } \\
& \text { dos dez melhores jornalistas brasileiros, pela } \\
& \text { preocupação com a informação, com o texto. } \\
& \text { (MORAES, 2007, p. 62). }
\end{aligned}
$$

José Carlos Marão, demissionário retornado, admite em seu livro de memórias que, apesar dos pesares, após a saída dos primeiros profissionais "foram feitas boas matérias, algumas até escolhidas para serem republicadas neste livro" (2010, p. 35). A referida coletânea reúne textos 
do autor publicados na revista Realidade até 1972. A maioria das edições temáticas, ápice da metodologia quantitativa, circulou na década de 1970, como a mencionada edição sobre a Amazônia, assim como Cidades Brasileiras (maio de 1972) e Nordeste (novembro de 1972).

Nos originais, constatamos que a primeira reformulação editorial de Realidade ocorre em agosto de 1970, quatro anos e meio depois de lançada. Trata-se de mudança menos decisiva do que a posterior, de outubro de 1973, editorialmente muito mais significativa. Essa segunda tentativa de reeditar Realidade diminuiu seu formato, a quantidade de anúncios e páginas, com o conteúdo passando a escancaradamente pasteurizado. Entre as chamadas de capa da edição que inaugura a última fase, há 0 apelo no alto da página para que 0 leitor "viva mais feliz, seja OK". 0 texto de apresentação, virando a capa, não poderia ser mais claro: "é com muito orgulho que a Editora Abril lança agora esta nova revista." Realidade deixaria de circular três anos depois, em 1976.

Diante desse marco da produção jornalística brasileira de dados, a bibliografia, sobretudo nacional, mereceria reajuste, como o manual traduzido e publicado pela Associação Brasileira de Jornalismo Investigativo (Abraji) em 2014. Segundo essa fonte, 0 uso de recursos quantitativos nas reportagens brasileiras teria começado na década de 1990. Não há menção, contudo, aos trinta anos de precedência de Realidade, nem aos vinte da criação do banco de dados que sustenta a tese principal de $\operatorname{Rota} 66$, narrativa sobre a polícia que mata inocentes (ZIBORDI, 2016).

\section{Jornalismo de dados em Realidade}

Para abordar a continuidade do jornalismo de dados em Realidade entre 1966 e 1973, precisamos de conceitos que não estejam circunscritos ao ambiente digital, o que alarga o horizonte histórico na narrativa numérica de informação e coloca em questão, antes como agora, "a incorporação de novas competências pelo campo jornalístico", conforme defendem Mancini e Vasconcellos (2016, p. 71). Para esses autores, restringir o jornalismo de dados ao ambiente digital "implicaria aceitar um argumento de natureza determinística" e "logo todo jornalismo com dados seria, necessariamente, Jornalismo de Dados, o que não nos parece correto" (p. 81).

Realidade investiu com regularidade na geração de estatísticas para produção de reportagens nos seis primeiros anos. Bem ou mal, fez jornalismo "de" dados, conforme a seguinte acepção:

Há uma diferença, a nosso ver, entre reportagens $C O M$ e reportagens $D E$ dados. Enquanto 0 primeiro contemplaria reportagens que se apropriam de dados de forma ilustrativa, no segundo caso, os dados seriam a própria razão da reportagem. No primeiro caso, o dado quantitativo teria o papel de auxiliar a ilustrar uma reportagem; no segundo, 0 dado seria o próprio fundamento da pauta e a história das relações entre os dados conduziria, neste caso, a reportagem. (MANCINI, VASCONCELLOS, 2016, p. 75). 
A imprensa produz com bases quantitativas desde antes dos computadores, mudando mais "em função do modo como definimos os dados (números, bits, etc.) e da maneira pela qual trabalhamos com eles (técnicas) do que por conta da aplicação ou não de uma tecnologia." (MANCINI, VASCONCELLOS, 2016, p. 75). Nessa perspectiva mais epistemológica do que tecnológica, consideraremos três "competências" ou "dimensões" aplicáveis à maneira de produzir jornalismo de dados nas reportagens e visualizações estatísticas de Realidade:

A dimensão investigativa (atuação proativa na busca de dados e revelações), a interpretativa (capacidade ou interesse em expor relações de causas ou consequências entre os dados) e a dimensão comunicativa (a centralidade da visualização do dado, compreendido aqui como um componente que ajuda o leitor a entender por imagens as relações entre os dados). (MANCINI, VASCONCELLOS, 2016, p. 81).

\footnotetext{
Ativar a "dimensão investigativa" implica buscar ou construir números que sustentem pautas relevantes de jornalismo de dados, competência que Realidade atende nas 30 reportagens, coligidas entre 1966 e 1973, se considerarmos a constância, a abrangência e 0 destaque editorial de levantamentos estatísticos consistentes realizados pela redação ou encomendados a empresas especializadas, na maior parte das vezes.
}

Numa segunda filtragem, percebemos que exatamente três dessas 30 edições apresentam somente dimensão investigativa. É quando a revista faz chamadas para levantamentos de dados, como a inserção de cartões de pesquisa em julho de 1966, na "primeira grande pesquisa de Realidade". A publicação perguntou aos leitores se eles eram contra ou a favor do divórcio².

Apesar de todas as edições proporem ou apresentarem investigações, e por isso atenderem à dimensão investigativa, que é propositiva, a abrangência e relevância dos levantamentos declina no período pesquisado, o que não excluiu coberturas de dados notáveis nas últimas edições analisadas, sobretudo no que diz respeito a gráficos e mapas. Desde a preparação do projeto editorial, a revista confiou nas estatísticas de opinião. Faro (1999, p. 45) informa que a publicação procurou saber das impressões de 500 leitores sobre o número zero, distribuído em novembro de 1965, antes da primeira edição oficial, em abril do ano seguinte. Moraes (2007, p. 120-125) menciona essa primeira pesquisa e uma segunda, realizada quatro meses após o lançamento, sondando a receptividade entre dois mil leitores.

Duas empresas produziram a maior parte dos dados utilizados em reportagens de Realidade nos seis primeiros anos: 0 Instituto de Estudos Sociais e Econômicos (INESE) e a Pesquisas e 
Estudos de Mercado Ltda. Marplan. A partir de 1970, a Azzi \& Marchi também passou a prestar serviços estatísticos.

Pensando na importância desse aporte profissional, inferimos que a exaltada genialidade da equipe inicial não frutificou somente de capacidades individuais nos dois primeiros anos da publicação, nem depois. A cobertura esteve aliada, desde 0 início, a um planejamento racional de produção, a começar pela lista de temas preferidos pelo público, apurada em pesquisas e amplamente atendida por inúmeras edições de Realidade. A revista soube se colocar no mercado. Ainda antecipando interpretações sobre a tabela a seguir, verificaremos variadas pautas baseadas em números aparecendo regularmente nos seis primeiros anos, em menor quantidade nas reportagens corriqueiras, concentradas em edições especiais e temáticas. Ao menos dois terços das matérias têm destaque na capa, metade como chamada principal, ou manchete. A revista não só produz, mas aposta no jornalismo de dados.

Quanto à quantidade de pessoas e lugares abarcados pelas reportagens estatísticas, são impressionantes ainda no início deste terceiro milênio, era dos grandes conjuntos de dados ("big data"), superiores à capacidade humana de processamento (LIMA JUNIOR, 2011, p. 50). Na primeira edição cuja reportagem principal traz números (pesquisa sobre a sexualidade da juventude, em agosto de 1966), foram compiladas 116 mil respostas. Outra cobertura especial, também censurada, sobre a mulher brasileira, cinco meses depois, tabulou 100 mil retornos de questionários com 110 perguntas. É também recorrente o esforço, nem sempre concretizado, em abranger capitais e interior do país, realizando a proeza de, na edição sobre a Amazônia, os repórteres percorrerem 131 cidades.

Se Realidade teve fôlego, sobretudo econômico, para gerar dados quantitativamente relevantes e produzir reportagens, do ponto de vista qualitativo, ao manipular estatísticas, seu desempenho nem sempre foi suficiente, apesar de melhorar nos seis primeiros anos. Considerando o que Mancini e Vasconcellos reclamam como "dimensão interpretativa" do jornalismo de dados (2016, p. 76), em Realidade a capacidade de narrar foi menor do que a de gerar as estatísticas.

Apesar de publicadas sob a rubrica "pesquisa", angariando respeitabilidade científica, muitas dessas reportagens numéricas são meras transcrições de dados, com pouca ou nenhuma interpretação. Material final burocrático, sem engendrar correlações. Para Mancini e Vasconcellos, a "dimensão interpretativa"

Procura não apenas apresentar 0 conteúdo da reportagem e o seu contexto, como, principalmente, se traz uma análise sobre as relações entre os dados de forma a indicar causas e/ou consequências do objeto da publicação. 0 texto pode ser tanto uma análise direta do jornalista como de entrevistados que são incluídos ao longo da reportagem e que cumprem o papel de analisar as relações entre os dados trazidos pela publicação. (2016, p. 76). 
Tabela 1: Edições e reportagens de dados em Realidade (1966-1973)

\begin{tabular}{|c|c|c|}
\hline Ano / Mês & Capa & Título / Metodologia \\
\hline $1966 \mathrm{Jul}$ & $X$ & $\begin{array}{l}\text { NOSSA PRIMEIRA GRANDE PESQUISA: VOTE A FAVOR OU CONTRA O DIVÓRCIO } \\
\text { Tiragem: } 450 \text { mil exemplares; encarte de cartão-resposta com opção a favor, a favor apenas do desquite, } \\
\text { ou contra ambos; elaboração do psiquiatra José Ângelo Gaiarsa; editora paga reenvio das respostas pelo Correio. }\end{array}$ \\
\hline 1966 Ago & $\mathrm{X}$ & $\begin{array}{l}\text { NOSSA JUVENTUDE DIANTE DO SEXO } \\
\text { Três meses de apuração em S. Paulo e Rio "pela primeira vez no Brasil"; } 116 \text { mil respostas, ouvidos } 1.000 \\
\text { estudantes de cursinhos, de } 15 \text { a } 18 \text { anos; elaboração do questionário pelo psiquiatra José Ângelo Gaiarsa. }\end{array}$ \\
\hline 1966 Nov & $\mathrm{X}$ & $\begin{array}{l}\text { BRASILEIROS QUEREM } 0 \text { DIVÓRCIO. } \\
\text { Recebidas } 14.600 \text { respostas Brasil inteiro. Pesquisa INESE. }\end{array}$ \\
\hline 1967 Jan & $\mathrm{X}$ & $\begin{array}{l}\text { EDIÇÃO ESPECIAL: A MULHER BRASILEIRA, HOJE } \\
\text { "Pesquisa": } 0 \text { que elas pensam e querem; } 100 \text { mil respostas tabuladas; } 10 \text { pesquisadores atuando durante } 40 \\
\text { dias; } 110 \text { questões a } 1.200 \text { mulheres do Rio, S. Paulo, B. Horizonte, P. Alegre, Recife e Caruaru (PE), Caxias (RS), } \\
\text { Juiz de Fora (MG), Bragança e Jundiaí (SP). Pesquisa INESE. }\end{array}$ \\
\hline 1967 Abr & $X$ & $\begin{array}{l}\text { ANTIAMERICANISM0 } \\
\text { "Pesquisa": } 0 \text { que pensa o povo; } 1.200 \text { maiores respondentes P. Alegre, Caxias (RS), Rio, S. Paulo, Jundiaí, Bragança } \\
\text { Pta. (SP), B. Horizonte, Juiz de Fora (MG) e Recife (PE). Três meses de levantamento, pesquisa INESE. }\end{array}$ \\
\hline 1967 Jun & & $\begin{array}{l}\text { ESTA CIDADE NÃO PAROU PARA PENSAR } \\
\text { Realidade colige inúmeros dados estatísticos sobre a cidade de São Paulo. }\end{array}$ \\
\hline $1967 \mathrm{Jul}$ & & $\begin{array}{l}\text { PERGUNTAS PARA A JUVENTUDE } \\
\text { Questionário encartado com } 19 \text { questões de múltipla escolha, editora paga reenvio pelo Correio. Pesquisa INESE. }\end{array}$ \\
\hline 1967 Set & $X$ & $\begin{array}{l}\text { EDIÇÃO ESPECIAL: A JUVENTUDE BRASILEIRA, HOJE } \\
\text { "Pesquisa" Marplan em S. Paulo e Rio, } 1.000 \text { pessoas + encarte em julho com } 20 \text { mil respostas, } \\
1.000 \text { selecionadas pelo INESE. }\end{array}$ \\
\hline 1967 Nov & & $\begin{array}{l}\text { QUANTO CUSTA } 0 \text { BRASIL } \\
\text { Realidade colige dados oficiais sobre o orçamento nacional. }\end{array}$ \\
\hline 1967 Dez & $X$ & $\begin{array}{l}\text { EXCLUSIVO: PELA PRIMEIRA VEZ NO BRASIL PESQUISA REVELA COMO } 0 \text { CONGRESSO VOTARIA SE PUDESSE } \\
\text { "Pesquisa": Jornalista Lúcio Gusmão Lobo entrevista } 246 \text { deputados e senadores em } 5 \text { meses; } \\
\text { questionário com } 66 \text { perguntas do Escritório de Ass. Técnica e Pesquisa. }\end{array}$ \\
\hline $1968 \mathrm{Abr}$ & $\mathrm{X}$ & $\begin{array}{l}\text { JUDEUS: } 0 \text { ANTISSEMITISMO NO BRASIL } \\
\text { "Pesquisa": } 20 \text { pesquisadores, } 1.000 \text { entrevistados, } 4 \text { semanas, Rio, S. Paulo e P. Alegre; pergunta aberta } \\
\text { "o que é um judeu", } 19 \text { múltipla escolha. Pesquisa INESE e socióloga Vera Lúcia Brisola. }\end{array}$ \\
\hline 1968 Mai & $X$ & $\begin{array}{l}\text { O PECADO ESTÁ MUDANDO } \\
\text { "Pesquisa": } 300 \text { respondentes em S. Paulo, Rio e Cambuí (MG); } 28 \text { questões de múltipla escolha. } \\
\text { Pesquisa INESE e sociólogo Luis Weis. }\end{array}$ \\
\hline 1968 Jul & $x$ & $\begin{array}{l}\text { RESPONDA: VOCÊ É A FAVOR DA EDUCAÇÃO SEXUAL? } \\
\text { Questionário encartado com } 17 \text { questões de múltipla escolha, editora paga Correio. }\end{array}$ \\
\hline 1968 Ago & & $\begin{array}{l}\text { "O MUNDO É AQUI LÁ FORA, ONDE ESTÃO TODAS AS COISAS" } \\
\text { Psicólogos entrevistam } 57 \text { meninos e meninas cariocas e paulistas entre } 4 \text { a } 6 \text { anos. } \\
\text { Coordenação do psicólogo José Inácio Parente. }\end{array}$ \\
\hline 1968 Nov & $x$ & $\begin{array}{l}\text { PESQUISA: SEXO SEM MEDO NA ESCOLA } \\
\text { Revista recebe } 24 \text { mil respostas de questionário encartado em julho, aproveita amostra de 10\%. } \\
\text { Dados “computados" pelo INESE. }\end{array}$ \\
\hline 1969 Mai & $X$ & $\begin{array}{l}\text { RESPONDA: COMO VAI } 0 \text { NOSSO ENSINO? } \\
\text { Questionário com } 31 \text { questões de múltipla escolha, editora paga envio das respostas. }\end{array}$ \\
\hline 1969 Set & $X$ & $\begin{array}{l}\text { AFINAL, O QUE QUEREM OS ESTUDANTES? Resultado de um grande inquérito } \\
\text { Amostra com } 2.000 \text { questionários, } 31 \text { questões a universitários de } 20 \text { a } 23 \text { anos. Pesquisa IBOPE e Instituto Téc. } \\
\text { de Análise de Pesquisas e Estudos (ITAPE). }\end{array}$ \\
\hline
\end{tabular}




\begin{tabular}{|c|c|c|}
\hline Ano / Mês & Capa & Título / Metodologia \\
\hline 1969 Dez & $x$ & $\begin{array}{l}\text { PESQUISA: QUE TAL } 0 \text { SEU HOMEM? } \\
\text { Marplan entrevista } 200 \text { cariocas e paulistas + } 30 \text { entrevistas realizadas pelo jornalista Luís Edgar de Andrade. }\end{array}$ \\
\hline 1970 Jan & $x$ & $\begin{array}{l}\text { AS CRIANÇAS JULGAM OS ADULTOS } \\
\text { Realidade entrevista } 100 \text { crianças de S. Paulo, Rio, Salvador, Recife, Belo Horizonte, Brasília e P. Alegre; Marplan } \\
\text { entrevista mais } 50 .\end{array}$ \\
\hline $1970 \mathrm{Fev}$ & $x$ & $\begin{array}{l}\text { PESQUISA-RESPOSTA: } 0 \text { HOMEM JULGA A MULHER BRASILEIRA } \\
\text { Marplan entrevista } 200 \text { homens; jornalista Rodolfo Konder, mais } 30 .\end{array}$ \\
\hline 1970 Jul & $x$ & $\begin{array}{l}\text { A TERRA DA GENTE. Os jovens, a mulher, as raças, os conquistadores. As imagens e as ideias do Brasil de hoje } \\
\text { "Pesquisa": } 0 \text { que o brasileiro pensa do Brasil + } 13 \text { reportagens. } 500 \text { pessoas ouvidas em S. Paulo, Rio, Brasília, } \\
\text { Recife e P. Alegre }+40 \text { questões Azzi \& Marchi e Luiz Weis. A cobertura ocupa } 180 \text { páginas. }\end{array}$ \\
\hline 1970 Jul & $x$ & $\begin{array}{l}\text { O BRASIL CRESCE. Balanço do presente, visão do futuro. Os recursos, os planos, os objetivos do nosso } \\
\text { desenvolvimento } \\
\text { Suplemento especial. Estatísticas da FGV + dados oficiais com análise de } 6 \text { economistas + } 11 \text { grandes seções de } \\
\text { "gráficos e quadros estatísticos". Realização IBRE (FGV). Cobertura tem } 332 \text { páginas. }\end{array}$ \\
\hline 1970 Ago & & $\begin{array}{l}\text { QUAL É } 0 \text { SEU GOSTO? } \\
\text { "Pesquisa-teste": } 25 \text { fotos de mulheres escolhidas por } 216 \text { homens do Rio e S. Paulo. }\end{array}$ \\
\hline 1971 Jun & $X$ & $\begin{array}{l}\text { SEU MÉDICO AFIRMA: VOCÊ É UM CHATO } \\
100 \text { médicos ouvidos no Rio e S. Paulo através de } 5 \text { questionários com } 49 \text { questões. Pesquisa Azzi \& Marchi. }\end{array}$ \\
\hline 1971 Out & $X$ & $\begin{array}{l}\text { AMAZÔNIA } \\
\text { Editor, } 16 \text { repórteres, } 7 \text { equipes, como cartografia. Cinco meses de cobertura: } 131 \text { cidades, } 30 \text { mil fotografias. } \\
\text { "Pesquisa": estrangeiros roubam a Amazônia? Rio, S. Paulo e P. Alegre, sem universo pesquisado (Azzi \& Marchi). } \\
18 \text { reportagens, entre outras entradas. Cobertura total tem } 328 \text { páginas. }\end{array}$ \\
\hline 1971 Nov & $x$ & $\begin{array}{l}\text { PESQUISA: SOMOS TODOS MEIO ESPÍRITAS. } \\
200 \text { entrevistados em S. Paulo e Rio. Pesquisa: Azzi \& Marchi + encarte de mapa da Bahia complementado com } \\
\text { pequenos textos históricos sobre } 0 \text { século } 18 .\end{array}$ \\
\hline 1972 Jan & & $\begin{array}{l}\text { A MODA É ESTUDAR } \\
\text { Reportagem tem dados sobre a escalada da educação no primário, médio e superior, além de informar valores de } \\
\text { recursos aplicados entre 1960-1970. }\end{array}$ \\
\hline 1972 Jan & & $\begin{array}{l}\text { QUEM ESTUDA QUER TRABALHO. QUE TRABALH0? } \\
\text { Realidade entrevista diretores de cinco "empresas de seleção de pessoal de alto nível, do Rio e de São Paulo" + } \\
\text { cruzamento dados empregados registrados 1970-71 + matriculados cursos superiores 1960-1970. }\end{array}$ \\
\hline 1972 Mai & $x$ & $\begin{array}{l}\text { NOSSAS CIDADES (Extra: um trabalho inédito: cinco supermapas que localizam os dramas urbanos das nossas } \\
\text { maiores metrópoles: Rio-São Paulo, Porto Algre, Belo Horizonte, Salvador e Recife.) } \\
\text { Apuração de } 6 \text { meses, } 4 \text { grandes seções, } 17 \text { reportagens. Exemplos de coberturas com dados: “As opiniões" (148 } \\
\text { curtos depoimentos Salvador, Rio, Brasilia, P. Alegre, S. Paulo, Recife, Belo Horizonte + } 17 \text { cidades interioranas); } \\
\text { "Nossas cidades" (Previsão: Brasil terá } 100 \text { milhões habitantes em } 21 \text { de agosto de 1972); "Nunca fomos tão } \\
\text { violentos" ( } 4 \text { questionários, } 23 \text { questões S. Paulo, Rio, Belo Horizonte, Nova Iguaçu, Curitiba, Florianópolis, Vitória } \\
\text { e Brasília); "0 que é Pasangua?" (supercidade, soma e projeção de dados, } 3 \text { meses, } 200 \text { histórias). Destaque para } \\
\text { os inúmeros mapas. Cobertura total tem } 228 \text { páginas. }\end{array}$ \\
\hline 1972 Nov & $x$ & $\begin{array}{l}\text { NORDESTE. } \\
\text { Equipe realiza } 4 \text { meses de pesquisa, repórteres percorrem } 173 \text { mil quilômetros. "Opiniões": } 83 \text { curtos } \\
\text { depoimentos colhidos em cidades nordestinas. Sem pesquisa específica realizada por empresas. Destaque para } \\
\text { inúmeros mapas. }\end{array}$ \\
\hline
\end{tabular}


Tentando evitar generalizações exageradas a partir de exemplos pontuais aos quais estamos circunscritos, quando apontamos os limites interpretativos do jornalismo de dados na revista Realidade pensamos, especialmente, em reportagens fundamentadas em pesquisa de opinião pública cujas narrativas oscilam entre extremos estilísticos do ponto de vista dos encaixes dos elementos que as compõem. Em agosto, na matéria sobre a sexualidade dos jovens brasileiros, a interpretação prepondera sobre a enxurrada de números, reservados aos quadros.

Ao contrário, na reportagem sobre divórcio, de novembro, 0 texto é composto pela concatenação mecânica de inúmeras respostas. Também burocrática, a narrativa principal do especial sobre a mulher brasileira, de janeiro de 1967; juncada de números, é ainda menos interessante no contexto da edição, em que as outras reportagens reverberam o premiado estilo de Realidade. Eis o parágrafo com os índices de resposta das mulheres à pergunta "a senhora acha que vivemos numa democracia?":

Aqui, as entrevistadas se dividem em duas partes quase iguais: $53 \%$ acham que sim; $45 \%$ disseram não; $2 \%$ não quiseram opinar. Do lado do sim estiveram as pobres (59\%), as de meia idade $(58 \%)$, as analfabetas $(69 \%)$, as casadas $(58 \%)$ e as católicas (55\%). Com o não ficaram as ricas $(63 \%)$, as jovens $(50 \%)$, as de nível universitário $(68 \%)$, as solteiras $(53 \%)$ e as sem religião (74\%).

Na próxima citação, ao contrário, constatamos as reconhecíveis qualidades de Realidade: narrativa orgânica que equilibra palavras e números, como a que compõe o especial sobre educação, de janeiro de 1972, exemplar ao atender à dimensão interpretativa:

Num trabalho exaustivo, Realidade localizou todos os engenheiros formados em 1970 pela Escola de Engenharia de Guaratinguetá, mantida pelo governo do Estado de São Paulo. Essa foi a primeira turma formada pela escola e todos os seus 34 alunos - uns com mais, outros com menos dificuldades, conseguiram emprego. A maioria em indústrias do Vale do Paraíba, outros absorvidos pela própria escola, para o magistério. Cinco deles conseguiram emprego no Centro Tecnológico da Aeronáutica e estão fazendo pós-graduação no ITA.

A passagem não é só informativa, é

contextualizadora: rastreia o passado e o presente de indivíduos relacionados, projetando futuro próspero à profissão de engenheiro. Exemplo de construção estilisticamente consequente, a expressão "todos" vem antes de "34" porque 0 texto pretende indicar a existência de um conjunto, depois a quantidade de componentes. A tentativa é de facilitar a compreensão ao estabelecer um raciocínio que vai do geral ao particular.

Na segunda parte do parágrafo, o mesmo movimento. Após informar a quantidade de alunos, a reportagem traz novas generalizações aproximativas ("a maioria", "outros") para pontuar em seguida: cinco engenheiros foram absorvidos pelo ITA. Em equilibrada racionalidade, os quatro períodos contêm duas construções textuais paralelas, uma no primeiro, outra no segundo par de orações. Ou seja, os encaixes dos elementos numéricos foram bem feitos. 
Antes de concluir esta seção, devemos relacionar a produção de narrativas com base em estatísticas em Realidade ao terceiro aspecto teórico que propusemos discutir, a "dimensão comunicativa" do jornalismo de dados, relativa à visualização dos conteúdos (MANCINI E VASCONCELLOS, 2016). Desse ponto de vista, o esforço em comunicar com imagens baseadas em dados nas edições dos primeiros anos atinge níveis de excelência, nos últimos. Se a qualidade textual foi decaindo até 1973, a visualização cresceu em importância e qualidade, principalmente na produção de mapas.

Quadros estatísticos estão presentes nas páginas de Realidade desde a edição sobre a sexualidade da juventude brasileira, de agosto de 1966, primeiro ano da publicação. Gráficos coloridos aparecem em reportagens de dados em novembro 1967 em matéria abordando o custo econômico do Brasil: são seis visualizações do que chamamos "gráficos de pizza", círculos com divisões a partir do centro, cada pedaço de uma cor. Ao contrário das narrativas visuais, 0 texto escrito, cheio de números, chega a ter um parágrafo inteiro composto só pelos valores de balanços de empresas.

Nos anos seguintes, nas reportagens de dados, Realidade manteria quadros com números ou resultados numéricos nas colunas de textos, em tópicos, em preto e branco, até que, na edição temática sobre as cidades brasileiras, em julho de 1970, reaparecem as visualizações coloridas nos resultados da "pesquisa" do mês, a opinião dos leitores sobre o país. Mais ousados e bem resolvidos editorialmente do que os gráficos, os mapas apareceram em Realidade em páginas desdobráveis, em papel mais grosso e nobre, como o primeiro deles, que acompanha a reportagem histórica sobre o levante baiano sufocado no final do século 18. Intitulada "A Bahia dos rebeldes", detalhada gravura realista em preto e branco, de 1801, é reproduzida em encarte com seis dobras e, no verso, temos a reconstituição fotográfica atualizada de Salvador.

0 mérito de Realidade está em compreender a relevância informacional da imagem e editar 0 material como encarte, enobrecendo a gravura original, que poderia figurar em qualquer representação visual de dados contemporânea, não só pela precisão do desenho, mas também dos dados: há 81 pontos numerados, e os locais aos quais se referem estão listados no rodapé da gravura - são pontos georreferenciados, diríamos atualmente. Outras visualizações notáveis como mapas ilustrados, montagem de fotos ou de imagens de satélites e desenhos didáticos, desdobráveis ou avulsos, serão valorizados nas duas edições especiais de 1972. Em maio, a capa sobre as cidades brasileiras chamava a atenção para 0 "trabalho inédito" de "cinco supermapas que localizam os dramas urbanos das nossas maiores metrópoles". hercúleo trabalho de repórteres em cada capital 
brasileira com mais de 1 milhão de habitantes.

Eles recolheram informações durante quatro meses: "A intenção, além de levantar material para documentar a atual situação de nossas cidades, era contar a vida dessas grandes metrópoles num mapa".

Nessa edição especial, a revista explica os objetivos, os métodos e a composição do "Departamento Cartográfico", que produziu os mapas. Mencionado no expediente de edições anteriores, até então não havia merecido reportagem específica. A narrativa sobre suas funções ocupou uma das primeiras páginas, com duas fotos. A publicação dos "cinco supermapas" justifica e valoriza a apresentação formal dos responsáveis pela cartografia, e vice-versa.

0 campo cartográfico é um setor relativamente esquecido e nem sempre incluído pelo jornalismo. Nele geralmente trabalha um grupo de profissionais extremamente dedicados, cujo amor pelo detalhe e pela informação precisa é tão ou mais exigente que 0 do mais conhecido dos jornalistas, o repórter.

0 mesmo Departamento produziria um mapa colorido com informações econômicas e datas festivas para a edição temática sobre 0 Nordeste, de novembro de 1972. É um encarte que funciona como guia turístico, como os que faziam sucesso na revista Quatro Rodas, da mesma Editora Abril. Nas páginas internas, três páginas desdobráveis mostram, em três fotos, a mata, 0 agreste e 0 sertão nordestinos. São silhuetas de animais em extinção recortadas num quadro panorâmico de um lado do encarte, com legendas explicativas ao redor; no verso, a imagem aparece completa.

Nesses exemplos, a revista estaria atendendo à "dimensão comunicativa" da lida com números, sabendo encaixar os encartes e outras narrativas visuais na sequencia informacional da edição:

Nessa categoria, procura-se identificar se as publicações trazem algum tipo de visualização, como gráficos ou infográficos. Avalia-se a maneira como essa visualização é utilizada de modo a permitir que o conteúdo da reportagem seja aprimorado pela comunicação visual, não no sentido estético, ainda que desejável, mas no sentido de que essa comunicação promova/ incentive a compreensão analítica da reportagem de dados (MANCINI, VASCONCELLOS, 2016, p. 76).

\section{É complexa a classificação das reportagens} nas dimensões interpretativa e comunicativa, sobretudo porque a maioria apresenta mais de um aspecto, equilibrados ou não. Predomina, entretanto, a interpretação sobre a comunicação. Consideramos que, de 30 reportagens analisados, em 16 a capacidade interpretativa atende aos quesitos semânticos de promover a compreensão, e sintáticos, relativos aos encaixes numéricos concatenados organicamente. ${ }^{3}$ 
Em geral, a dimensão interpretativa se sobrepõe à comunicativa, apesar de esta crescer no final do período analisado, na década de 1970, sobretudo com visualizações de dados em infográficos, quadros, mapas e charges. Em poucas coberturas verificamos o predomínio comunicativo, exatamente em quatro edições ${ }^{4}$. Em outras, consideramos equilibradas as soluções ou os problemas editoriais. São casos em que o texto pode ser fluente, sem excessos numéricos, e a visualização de dados criou narrativas bem resolvidas. Ou ocorreu o contrário: as duas dimensões foram igualmente mal atendidas. Enquadramos cinco edições nesse contexto ${ }^{5}$.

Feita a crítica das técnicas estatísticas e jornalísticas, e classificadas as reportagens de dados, passemos à discussão dos usos discursivos nos sete primeiros anos da revista Realidade. 0 debate gira em torno da promoção alienada de estatísticas como verdades finais.

\section{Ficções sem literatura}

A ousada e diversas vezes competente produção de reportagens estatísticas e visualizações de dados em Realidade fez mais do que narrativas: promoveu discurso noticioso (VAN DIJK, 1990) segundo o qual os números enunciam verdades inquestionáveis porque têm base científica. Nas reportagens e visualizações de dados publicadas nos sete primeiros anos de circulação da revista, encontramos inúmeras expressões promocionais em palavras como "documento", "mostra científica", "provas", "verdade", "realidade", "avaliação exata".

Conforme discutem autores como Bourdieu (1981) e Besson (1995), as estatísticas produzem efeitos pouco ou nada racionais, como ilusões, inverdades, reduções, generalizações, distorções. 0 discurso jornalístico enunciado a partir dos números em Realidade, todavia, expressa certezas.

As problematizações do conteúdo são possíveis desde as pautas principais a serem esquadrinhadas numericamente, depois transformadas em reportagens. Besson nos lembra de que as estatísticas melhores custam caro e, às vezes, o custo é "proibitivo" (1995, p. 28), enquanto outro autor francês nota que poucas instituições têm condições econômicas para bancar grandes levantamentos estatísticos. Para Bourdieu, "as problemáticas que são propostas pelas pesquisas de opinião subordinam-se a interesses políticos, e isso

São elas de novembro e dezembro de 1967, junho de 1970 e junho de 1971.

São elas de agosto de 1966, janeiro de 1967, abril de 1968, setembro de 1969 e agosto de 1970.

Respectivamente nas edições de novembro 1966, p. 93; abril de 1967, p. 19; abril de 1968, p. 101; agosto de 1970, p. 03; julho de 1970, editorial; novembro de 1971, p. 73. 
dirige de maneira muito acentuada 0 significado das respostas e, ao mesmo tempo, o significado dado à publicação dos resultados." (p. 139).

Os temas pautados por Realidade eram antes significativos para a própria revista, representada por seu corpo editorial e o público culto dos grandes centros. E diziam bem pouco se considerarmos toda a população do país, apesar de chamadas generalizantes como "A mulher brasileira, hoje". Nessa edição, de janeiro de 1967, a expressiva quantidade de 110 mil respostas tabuladas cobre somente cinco Estados. As principais preocupações das mulheres das metrópoles, como divórcio e entrada no mercado de trabalho, certamente não eram as mesmas das interioranas do Amapá. Porém, a maneira como a estatística é publicada por Realidade, a começar pelas manchetes, fez crer que sim.

Por isso, em vez de vermos a revista como a principal vocalizadora jornalística dos grandes temas de interesse nacional sufocados nos primeiros anos de regime militar, consideramos a publicação como enunciadora de pautas da classe média dos grandes centros urbanos, sobretudo Rio de Janeiro e São Paulo, as cidades mais pesquisadas para a produção de reportagens de dados publicadas por Realidade.

Bourdieu e Besson notam ainda outro reducionismo das estatísticas. Ao formular questões tidas como de interesse geral, as pesquisas fazem supor que há consenso sobre os problemas discutidos. No caso de Realidade, mesmo induzindo os leitores a acreditarem que estavam diante da opinião nacional, a revista conversava com as classes médias das principais cidades brasileiras, como indicam os dados de circulação, vendagem e assinaturas. A neutralidade encenada pelos levantamentos estatísticos compõe o discurso noticioso com colocações peremptórias do tipo: "as técnicas mais modernas de investigação foram utilizadas na apuração dos fatos. A análise dos dados, conduzida com isenção e seriedade pelo Departamento de Pesquisa".

Levantamentos estatísticos isentos são impossíveis, por diversos motivos. Besson assinala que as pesquisas não refletem a realidade, mas "0 olhar da sociedade sobre si mesma" (p. 19). Pesquisadores e informantes são falíveis; é impossível medir 0 grau de inexatidão, apesar da dramatização construída pela síntese numérica pinçando dados bombásticos, constatações ou previsões abaladoras em enunciados com destaque gráfico: tamanho e localização privilegiados, cores fortes.

Estatísticas não são totalmente verdadeiras nem falsas, são relativas, matização que Realidade jamais considerou seriamente. Segundo Bourdieu, a função das pesquisas de opinião "consiste talvez em impor a ilusão de que existe uma opinião pública que é a soma puramente aditiva de opiniões individuais". É como "impor a ideia de 
que existe algo que seria uma coisa assim como a média das opiniões ou a opinião média" (p. 140). Em Realidade, essa opinião geral e generalizável começa nas manchetes, como pudemos constatar na tabela anterior, exemplar em chamadas como a da capa de novembro de 1971: "Pesquisa: somos todos meio espíritas". A estatística que embasou tal conclusão nacional reúne a opinião de 200 entrevistados em São Paulo e Rio de Janeiro.

Conforme ensina Besson, um equívoco de base é não perceber que "todo questionário recolhe declarações e não fatos" (1995, p. 90). A opinião é tomada de interlocutores muito diferentes, abordados em diversos locais e circunstâncias. Uma das maneiras de suprimir a complexidade da situação de coleta é eliminar as respostas que não haviam sido previstas, em benefício da construção de um sentido lógico, estável.

Não se pode saber exatamente como as perguntas são interpretadas pelos respondentes, mas eles certamente não respondem sempre a mesma questão. Para Bourdieu, "um dos efeitos mais perniciosos da pesquisa de opinião consiste precisamente em colocar pessoas respondendo perguntas que elas não se perguntaram" (p. 141). A cada questionário aplicado ocorre um indescritível jogo de proximidade e distanciamento entre perguntador e respondente, entre perguntas e respostas.

A situação de pesquisa é "inteiramente artificial", apesar de, em Realidade, as estatísticas figurarem como retrato fiel, a exemplo do subtítulo da edição especial "A terra da gente", de julho de 1970: "Os jovens, a mulher, as raças, os conquistadores. As imagens e as ideias do Brasil de hoje". Não se trata, contudo, do país como ele é, mas o país tal qual a publicação o retratou.

Besson e Bourdieu chegam a conclusões semelhantes, ambas úteis na desmistificação do discurso de verdade da revista Realidade nas reportagens de jornalismo de dados nos seis primeiros anos. Para eles, a opinião pública simplesmente não existe, "pelo menos na forma que lhe atribuem os que têm interesse em afirmar sua existência", afirma Bourdieu (1981, p. 151). Para Besson, os institutos de pesquisa "estão longe de registrar, como pretendem, 'estados de opinião'. Eles contribuem, sobretudo, para que se acredite que existe, sobre tudo ou quase tudo, uma 'opinião pública”' (1995, p. 232).

Entre contribuições inegáveis para a linguagem jornalística e para o debate entre as classes médias leitoras da revista nos grandes centros urbanos, Realidade serviu também para que seu público imaginasse que, no Brasil da Ditadura, a opinião pública circulava um pouco mais do que ela realmente circulava.

\section{Objetivamente falando}

\section{Conforme apontamos, a revista Realidade} gerou dados para produção de reportagens na imprensa brasileira desde 1966. Ao tentarmos 
uma interpretação do conjunto dessas narrativas numéricas, notamos seu pendor positivista, padecendo de reducionismos que afligem contemporaneamente a atividade jornalística e científica. São heranças comuns, como "a tendência para diagnosticar o acontecimento social no âmbito da invariabilidade das leis naturais", "a busca obsessiva pela precisão dos dados como valor de mercado" e a "delimitação de fatos determinados" (MEDINA, 2008, p. 24-25), exatamente com fez Realidade na maioria das reportagens de dados publicadas nos seis primeiros anos.

A farta publicidade também professou fé na geração eletrônica de estatísticas. Em anúncio de página dupla de julho de 1970, a IBM alardeia suas contribuições ao progresso nacional visando a "reduzir a burocracia, diminuir as horas de trabalho e imprimir velocidade e total confiabilidade ao processo". Segundo o anúncio, "vivemos - interna e externamente - uma crescente demanda de máquinas de processamento de dados" (p. 244-245).

É praticamente a mesma afirmação que consta em página jornalística de Realidade em julho de 1970: "o Brasil caminha firmemente para grandes amanhãs. 0s frutos do planejamento racional e da eficiência administrativa começam a ser colhidos, tanto no campo governamental, quanto no da iniciativa privada". 0 público reconhece esse discurso desde que Realidade começou a circular. Em carta à redação publicada em fevereiro de 1967, um leitor comentou a abordagem honesta da revista em assuntos vitais "norteando-se sempre por critérios científicos".

Ao contrário do ponto de vista do leitor ingênuo, nas reportagens de dados de Realidade verificamos aquilo que pode ser diagnosticado como "déficit de entendimento da trama complexa do presente" (MEDINA, 2008, p. 61) com a revista pautada pelos mesmos paradigmas racionais, de viés estatístico, que norteavam o Estado autoritário, supostamente enfrentado pela publicação.

Ao lidar com números, Realidade comportou-se como os burocratas do governo; ou, conforme interpretação de Faro sobre as reportagens de economia, "a esse tema estavam associados fragmentos discursivos importantes de toda a articulação ideológica que o Estado pretendia promover, e sua vinculação à racionalidade que 0 autoritarismo permitia" (1999, p. 194).

\section{Referências}

BOURDIEU, Pierre. A opinião pública não existe. In: THIOLLENT, Michel. Crítica Metodológica, investigação social e enquete operária. São Paulo: Polis, 1981. p. 137-151.

BESSON, Jean-Louis Besson (Org.). A ilusão das estatísticas. São Paulo: Editora Unesp, 1995.

CHRISTOFOLETTI, Rogério, KARAM. José Francisco (Orgs.). Jornalismo investigativo e pesquisa científica: fronteiras. Florianópolis: Insular, 2015.

FARO, José Salvador. Revista Realidade, 1966-1968: tempo da reportagem na imprensa brasileira. Canoas: Editora da Ulbra/AGE, 1999. 
FERREIRA, Tiago da Silva. Revista Realidade: gênero e sexualidade na imprensa brasileira (19661968). Dissertação de mestrado. Universidade Federal Fluminense, Niterói, 2013.

FREIRE, Roberto. Eu é um outro. Salvador:

Maianga, 2002.

GRAY, Jonathan; CHAMBERS, Lucy; BOUNEGRU, Liliana (orgs.). Manual de jornalismo de dados: como os jornalistas podem usar dados para melhorar suas reportagens. Abraji, 2014. Disponível em http:// datajournalismhandbook.org/pt/. Acesso em 23 jan. 2018.

KUCINSKI, Bernardo. Jornalistas e revolucionários: nos tempos da imprensa alternativa. São Paulo: Edusp, 2003.

LIMA, Edvaldo Pereira. Páginas ampliadas: 0 livroreportagem como extensão do jornalismo e da literatura. Ed. revista e atualizada. Barueri: Manole, 2009.

LIMA JR., Walter Teixeira. Jornalismo computacional em função da "Era do Big Data". Revista Líbero, v. 14, n. 28, p. $45-52$, dez. 2011

LOPES, Ana Cristina, REIS, Carlos. Dicionário de teoria narrativa. São Paulo: Ática, 1988.

MANCINI, Leonardo, VASCONCELLOS, Fábio.

Jornalismo de dados: conceitos e categorias. Revista Fronteiras - Estudos Midiáticos, São Leopoldo, v. 18, n. 1, p. 69-82, jan./abr., 2016.

MARÃ0, José Carlos, RIBEIR0, José Hamilton.

Realidade re-vista. Santos: Realejo Edições. 2010.

MEDINA, Cremilda. Ciência e jornalismo: da herança positivista ao diálogo dos afetos. São Paulo: Summus, 2008.

MORAES, Letícia Nunes de. Leituras da Revista Realidade (1966-1968). São Paulo: Alameda, 2007. RODRIGUES, Fernando. Políticos do Brasil: uma investigação sobre o patrimônio declarado e a ascensão daqueles que exercem o poder. São Paulo: Publifolha, 2006.

SEVERIANO, Mylton. Leituras da revista Realidade. São Paulo: Alameda, 2007.

TODOROV, Tzvetan. As estruturas narrativas. São Paulo: Perspectiva, 1996.

Estruturalismo e poética. São Paulo:

Perspectiva, 1971.

VAN DIJK, Teun A. La noticia como discurso.

Compresión, estructura y producción de la información. Barcelona: Paidós, 1990.

ZIBORDI, Marcos. Livro-reportagem Rota 66: pioneirismo, metodologia e narrativa. Líbero, São Paulo, v. 19, n. 38, p. 121-130, jul./dez., 2016. 


\begin{tabular}{|c|c|}
\hline $\begin{array}{l}\text { Data journalism in } \\
\text { Realidade magazine }\end{array}$ & $\begin{array}{l}\text { Periodismo de datos } \\
\text { en la revista Realidad }\end{array}$ \\
\hline $\begin{array}{l}\text { Abstract } \\
\text { It is intended to discuss the production of reports } \\
\text { based on statistics between 1966, the year of the } \\
\text { debut of the magazine Realidade, and 1973, when } \\
\text { it changed radically. From the query to originals we } \\
\text { collect information such as regularity, extension and } \\
\text { methodology of numerical reporting, classifying } 40 \% \\
\text { as "data journalism". His decisive presence confronts } \\
\text { the idea of a magazine made of journalistic-literary } \\
\text { narratives, produced by irreplaceable team in the } \\
\text { first two years. The conclusions are mainly due to } \\
\text { the application of Mancini and Vasconcellos' analysis } \\
\text { parameters (2016), according to which numerical } \\
\text { narratives must meet three "dimensions": investigative, } \\
\text { interpretative and communicative. } \\
\text { Keywords } \\
\text { Realidade Magazine. Data journalism. Report. }\end{array}$ & $\begin{array}{l}\text { Resumen } \\
\text { Se pretende discutir la producción de reportajes con } \\
\text { base estadística entre 1966, año de estreno de la revista } \\
\text { Realidad, y 1973, cuando cambió radicalmente. De la } \\
\text { consulta a originales recolectamos informaciones como } \\
\text { regularidad, extensión y metodología de los reportajes } \\
\text { numéricos, clasificando el 40\% como "periodismo de } \\
\text { datos". Su decisiva presencia confronta la idea de una } \\
\text { revista tomada de narrativas periodístico-literarias, } \\
\text { producidas por insustituible equipo en los dos primeros } \\
\text { años. Las conclusiones se derivan, sobre todo, de la } \\
\text { aplicación de los parámetros de análisis de Mancini } \\
\text { y Vasconcellos (2016), según los cuales narrativas } \\
\text { numéricas deben atender a tres "dimensiones": } \\
\text { investigativa, interpretativa y comunicativa. } \\
\text { Palabras-clave } \\
\text { Revista Realidade. Jornalismo de datos. Reportero. }\end{array}$ \\
\hline
\end{tabular}




\section{Expediente}

A revista E-Compós é a publicação científica em formato eletrônico da Associação Nacional dos Programas de Pós-Graduação em Comunicação (Compós). Lançada em 2004, tem como principal finalidade difundir a produção acadêmica de pesquisadores da área de Comunicação, inseridos em instituições do Brasil e do exterior.

\section{E-COMPÓS I www.e-compos.org.br I E-ISSN 1808-2599}

Revista da Associação Nacional dos Programas de Pós-Graduação em Comunicação. Brasília, v.21, n.3, set/dez. 2018. A identificação das edições, a partir de 2008, passa a ser volume anual com três números. Indexada por Latindex I www.latindex.unam.mx

\section{CONSELHO EDITORIAL}

Ada Cristina Machado Silveira, Universidade Federal de Santa Maria, Brasi Alda Cristina Silva da Costa, Universidade Federal do Pará, Brasil Alfredo Luiz Paes de Oliveira Suppia, Universidade Estadual de Campinas, Brasil Ana Carolina Rocha Pessôa Temer, Universidade Federal de Goiás, Brasil Ana Regina Barros Rego Leal, Universidade Federal do Piauí, Brasil André Luiz Martins Lemos, Universidade Federal da Bahia, Brasil Angela Cristina Salgueiro Marques, Universidade Federal de Minas Gerais, Brasil Ângela Freire Prysthon, Universidade Federal de Pernambuco, Brasil Anna Cristina Pertierra, Western Sidney University, Austrália Antonio Carlos Hohlfeldt, Pontifícia Universidade Católica do Rio Grande do Sul, Brasi Arthur Ituassu, Pontifícia Universidade Católica do Rio de Janeiro, Brasil Bruno Campanella, Universidade Federal Fluminense, Brasil Bushra Hameedur Rahman, University of the Punjab, Paquistão, Paquistão Cárlida Emerim, Universidade Federal de Santa Catarina, Brasil Carlos Del Valle Rojas, Universidad de La Frontera, Chile Carlos Eduardo Franciscato, Universidade Federal de Sergipe, Brasil Cláudio Novaes Pinto Coelho, Faculdade Cásper Líbero, Brasil Danilo Rothberg, Universidade Estadual Paulista, Brasil Denise Tavares, Universidade Federal Fluminense, Brasil Diógenes Lycarião, Universidade Federal do Ceará, Brasil Dóris Martínez Vizcarrondo, Universidad de Puerto Rico Mayagüez, Porto Rico Eduardo Vicente, Universidade de São Paulo, Brasil

Eliza Bachega Casadei, Escola Superior de Propaganda e Marketing - SP, Brasil Elvira Gomes dos Reis Freitas, Universidade de Cabo Verde, Cabo Verde Eneus Trindade, Universidade de São Paulo, Brasil Erick Felinto de Oliveira, Universidade do Estado do Rio de Janeiro, Brasil Erick Torrico, Universidad Andina Simón Bolívar, Bolívia, Bolívia Erly Vieira Júnior, Universidade Federal do Espírito Santo, Brasil Fabio La Rocca, Université Paul-Valéry Montpellier 3, França Fernando Firmino da Silva, Universidade Federal da Paraíba, Brasil Francisco de Assis, FIAM-FAAM Centro Universitário, Brasil Francisco Elinaldo Teixeira, Universidade Estadual de Campinas, Brasil Francisco Gilson Rebouças Pôrto Junior, Universidade Federal do Tocantins, Brasil Francisco Sierra Caballero, CIESPAL, Equador Frederico de Mello Brandão Tavares, Universidade Federal de Ouro Preto, Brasil Gabriela Reinaldo, Universidade Federal do Ceará, Brasil Germán Rey Beltrán, Universidad Nacional de Colombia, Colômbia Gilson Vieira Monteiro, Universidade Federal do Sul da Bahia, Brasil Gustavo Daudt Fischer, Universidade do Vale do Rio dos Sinos, Brasil Gustavo Hernández Díaz, Universidad Central de Venezuela, Venezuela Heidi Figueroa Sarriera, Universidad de Puerto Rico, Porto Rico Ignacio Aguaded, Universidad Huelva, Espanha Inesita Soares de Araújo, FIOCRUZ, Brasil Itania Maria Mota Gomes, Universidade Federal da Bahia, Brasil Jiani Adriana Bonin, Universidade do Vale do Rio dos Sinos, Brasi João Carlos Ferreira Correia, Universidade da Beira Interior, Portugal Jonathan Cohen, University of Haifa, Israel José Afonso da Silva Junior, Universidade Federal de Pernambuco, Brasil José Luiz Aidar Prado, Pontifícia Universidade Católica de São Paulo, Brasil Josette Maria Monzani, Universidade Federal de São Carlos, Brasil Juçara Gorski Brittes, Universidade Federal de Ouro Preto, Brasil Julián Durazo Hermann, Université du Québec à Montreal, Canadá Juliana Freire Gutmann, Universidade Federal da Bahia, Brasil
Karla Yolanda Covarrubias, Universidad de Colima, México Laura Loguercio Cánepa, Universidade Anhembi Morumbi, Brasil Leonel Azevedo de Aguiar, Pontifícia Universidade Católica do Rio de Janeiro, Brasil Leticia Cantarela Matheus, Universidade do Estado do Rio de Janeiro, Brasil Ling Chen, Hong Kong Baptist University, China Luciana Coutinho Souza, Universidade de Sorocaba, Brasil Marcel Vieira Barreto Silva, Universidade Federal da Paraíba, Brasil Marcia Tondato, Escola Superior de Propaganda e Marketing, Brasil Márcio Souza Gonçalves, Universidade do Estado do Rio de Janeiro, Brasil Maria Ataide Malcher, Universidade Federal do Pará, Brasil Maria das Graças Pinto Coelho, Universidade Federal do Rio Grande do Norte, Brasi Maria Elena Hernández Ramirez, Universidad de Guadalajara, México Maria Elisabete Antonioli, Escola Superior de Propaganda e Marketing - SP, Brasil Maria Teresa Quiroz, Universidad de Lima, Peru Marialva Carlos Barbosa, Universidade Federal do Rio de Janeiro, Brasil Marina Poggi, Universidad Nacional de Quilmes, Argentina Marli Santos, Faculdade Cásper Líbero, Brasil Mateus Yuri Passos, Universidade Metodista de São Paulo, Brasil Mauricio Mario Monteiro, Universidade Anhembi Morumbi, Brasil, Brasil Mayka Castellano, Universidade Federal Fluminense, Brasil Mirta Varela, Universidad de Buenos Aires, Argentina

Mozahir Salomão Bruck, Pontifícia Universidade Católica de Minas Gerais, Brasil Neyla Graciela Pardo Abril, Universidad Nacional de Colombia, Colômbia Nísia Martins Rosario, Universidade Federal do Rio Grande do Sul, Brasil Olga Guedes Bailey, Nottingham Trent University, Reino Unido Paolo Demuru, Universidade Paulista, Brasil

Paolo Peverini, LUISS, Itália

Paško Bilić, Institute for Development and International Relations, Croácia Paula Melani Rocha, Universidade Estadual de Ponta Grossa, Brasil Potiguara Mendes Silveira Jr, Universidade Federal de Juiz de Fora, Brasil Rafael Cardoso Sampaio, Universidade Federal do Paraná, Brasil Rafael Tassi Teixeira, Universidade Tuiuti do Paraná, Brasil Regiane Lucas de Oliveira Garcêz, Universidade Federal de Minas Gerais, Brasil Regiane Regina Ribeiro, Universidade Federal do Paraná, Brasil Renata Pitombo Cidreira, Universidade Federal do Recôncavo da Bahia, Brasil Renato Essenfelder, Escola Superior de Propaganda e Marketing, Brasil Roberto Elísio dos Santos, Universidade Municipal de São Caetano do Sul, Brasil Robson Borges Dias, Universidade Católica de Brasília (UCB), Brasil Rodolfo Rorato Londero, Universidade Estadual de Londrina, Brasil Rosario Sanchéz Vilela, Universidad Católica del Uruguay, Uruguai Roseli Figaro, Universidade de São Paulo, Brasil Saima Saeed, Jamia Millia Islamia, India Sara Brandellero, Leyden University, Holanda Simone Maria Andrade Pereira de Sá, Universidade Federal Fluminense, Brasil Sônia Caldas Pessoa, Universidade Federal de Minas Gerais, Brasil Sun Sun Lim, Singapore University of Technology and Design, Singapura Tatiana Oliveira Siciliano, Pontifícia Universidade Católica do Rio de Janeiro, Brasil Thaïs de Mendonça Jorge, Universidade de Brasília, Brasil Valquiria Michela John, Universidade Federal do Paraná, Brasil Vicky Mayer, Tulane University, Estados Unidos da América do Norte Yamile Haber Guerra, Universidad de Oriente, Cuba 


\section{CONSELHO CIENTÍFICO}

Cristiane Freitas Gutfreind, Pontifícia Universidade Católica do Rio Grande do Sul, Brasil I Eduardo Antonio de Jesus, Universidade Federal de Minas Gerais, Brasil I Eduardo Morettin, Universidade de São Paulo, Brasil I Irene de Araújo Machado, Universidade de São Paulo, Brasil

\section{COMISSÃO EDITORIAL}

Igor Pinto Sacramento, Universidade Federal do Rio de Janeiro, Brasil I Kelly Cristina de Souza Prudencio, Universidade Federal do Paraná, Brasil | Miriam de Souza Rossini, Universidade Federal do Rio Grande do Sul, Brasil

\section{EDITORES ASSOCIADOS}

Rafael Grohmann, Faculdade Cásper Líbero, Brasil I Thaiane Moreira de Oliveira, Universidade Federal Fluminense, Brasil

\section{CONSULTORES AD HOC}

Ada Machado, Universidade Federal de Santa Maria, Brasil | Ana Carolina Escosteguy, Universidade Federal de Santa Maria, Brasil | Andrea França, Pontifícia Universidade Católica do Rio de Janeiro, Brasil | Ariane Holzbach, Universidade Federal Fluminense, Brasil | Benjamim Picado, Birkbeck College, Inglattera | Bruno Souza Leal, Universidade Federal de Minas Gerais, Brasil I Eduardo Morettin, Universidade de São Paulo, Brasil I Felipe Trotta, Universidade Federal Fluminense, Brasil | Francisco Rüdiger, Pontifícia Universidade Católica do Rio Grande do Sul, Brasil | Gislene da Silva, Universidade Federal de Santa Catarina, Brasil | Inês Vitorino, Universidade Federal do Ceará, Brasil I Isaltina Gomes, Universidade Federal de Pernambuco, Brasil I Jairo Ferreira, Universidade do Vale do Rio dos Sinos, Brasil I Karina Janz, Universidade Estadual de Ponta Grossa, Brasil | Kati Caetano, Universidade Tuiuti do Paraná, Brasil | Lilian França, Universidade Federal do Sergipe, Brasil | Liziane Guazina, Universidade de Brasília, Brasil I Márcio de Vasconcellos Serelle, Pontifícia Universidade Católica de Minas Gerais, Brasil I Marta Maia, Universidade Federal de Ouro Preto, Brasil I Maurício de Bragança, Universidade Federal Fluminense, Brasil I Nina Velasco e Cruz, Universidade Federal de Pernambuco, Brasil | Norval Baitello Jr., Pontifícia Universidade Católica de São Paulo, Brasil | Pedro Guimarães, Universidade do Estado do Rio de Janeiro, Brasil | Priscilla Perazzo, Universidade Municipal de São Caetano do Sul, Brasil I Sofia Zanforlin, International Association of Media and Communication Research, Estados Unidos I Talitha Ferraz, Escola Superior de Propaganda e Marketing, Brasil I Tattiana Teixeira, Universidade Federal de Santa Catarina, Brasil I Victa de Carvalho Pereira da Silva, Universidade Federal do Rio de Janeiro, Brasil

\section{EQUIPE DE EDITORAÇÃO}

ASSISTENTE EDITORIAL Marcio Telles I REVISÃO DE TEXTOS Fátima Áli | EDITORAÇÃO ELETRÔNICA Roka Estúdio

COMPÓS I www.compos.org.br

Associação Nacional dos Programas de Pós-Graduação em Comunicação

Presidente

Marco Roxo

Programa de Pós-Graduação em Comunicação - UFF

marcos-roxo@uol.com.br

Vice-Presidente

Isaltina Gomes

Programa de Pós-Graduação em Comunicação - UFPE

isaltina@gmail.com

Secretária-Geral

Gisela Castro

Programa de Pós-Graduação em Comunicação

e Práticas de Consumo - ESPM

castro.gisela@gmail.com

CONTATO I revistaecompos@gmail.com 